\title{
Actuarial-based Public Pension Systems
}

\section{Richard Disney}

Conference

"Democracy, Sustainability and Policy Reform"

CERGE-EI, November 15, 2004 

First draft 11 November 2004

For conference organised by CEFRES, CERGE-EI and EUREQua

at Prague, November 15, 2004

\section{Actuarial-based public pension systems}

\section{Richard Disney*}

\section{Introduction}

In employer-provided pension plans and individual retirement saving accounts, contributions over the working lifetime are used to purchase assets that are drawn down after retirement. In contrast, public pension systems typically do not accumulate substantial funds of assets to back future pension liabilities, and use Payas-you-go (PAYG) finance. With PAYG finance, current revenue to the programme, which may be derived from a tax specifically levied on payroll or from general taxation, is used to finance current pension expenditure. Such a pension programme is therefore a form of tax-and-transfer system, akin to other elements of the public welfare programme.

With the exception of a few countries such as Australia, however, public pension systems differ from public welfare programmes designed simply as a tax-andtransfer system designed to compensate those with inadequate private resources. More commonly, by an explicit analogy with private pension plans, public programme entitlements are contribution-based, in the sense that participants' contributions accrue implicit 'rights' to a specific benefit level on retirement that will be paid by later taxpayers, even if no actual fund of contributions is accumulated.

In the United Kingdom, for example, the National Insurance system, initiated in 1911 and extended universally in 1946, is a 'social insurance' programme that differs from a private programme insofar as risks (of differential longevity) are pooled across contributors. Contributions levied on payroll are notionally allocated to a

\footnotetext{
Professor of Economics, University of Nottingham, Nottingham, United Kingdom, and Research Fellow, Institute for Fiscal Studies, London. This is a draft of a chapter scheduled to appear in the Oxford Handbook of Pensions and Retirement Income (editors Gordon Clark, Alicia H Munnell and Michael Orszag).
} 
'National Insurance Fund' (which in fact only contains a few months of reserves). The value of the participant's contributions determines his or her benefits on retirement based on an explicit formula related to annual earnings levels, years of contributions and indexation factors.

In France (since 1945) and Germany (in more recent times), this link between contributions and pensions has been even more explicit through a points-based system. Each year's individual contributions accumulate 'points' which, on an individual's retirement, are converted into a pension by an explicit formula. In similar vein to 'social insurance' in the UK, contribution-based pension entitlements financed from current taxes in continental European countries reflect intergenerational 'solidarity', making explicit the link between generations which is implicit in pension provision, whether funded or tax-financed.

It could be argued that portraying public pension systems as 'social insurance' or 'solidaristic' vehicles is merely a smokescreen behind which governments persuade taxpayers that taxes levied to pay for other people's pensions are actually contributions to their own pensions - in other words, a revenue-raising device. Governments can, by administrative decisions, arbitrarily change the value of 'accumulated' contributions when there are no assets backing those claims, as UK pensioners learnt to their cost during the Conservative administrations of the 1980s and early 1990s and as reflected in the arbitrary revaluations of individual accumulated 'points' in the French system according to financial exigencies and electoral pressures.

Nevertheless, the analogy between public and private contribution-based systems raises interesting questions for public pension policy that are the focus of this essay. Does it matter whether tax-financed public pension systems look more like private insurance-based programmes or operate as tax-and-transfer programmes in which money is explicitly taken from workers simply to pay current pensions? The distinction might matter if it was believed that public pension programmes that mimic private insurance-based programmes had favourable incentive effects on participant's behaviour. The closer the notional link between an individual's contributors and their public pension, it is sometimes argued, the less the system is like a tax-and-transfer programme and the more it is like a 'pure' retirement saving programme - which I will term here an actuarial-based system. Since individuals do not normally perceive 
contributions to a retirement saving programme in the same way as they perceive taxes, the lower the 'tax component' of the system, the greater the potential for positive incentive effects on, for example, labour supply. This point is formally illustrated in the next section, although its practical significance is an empirical matter.

Second, it is sometimes argued, tax-financed actuarial-based public pension systems also have features that enable them better to absorb macroeconomic 'shocks' (particularly the onset of demographic ageing and the consequent financial strain caused to public pension systems by declining support ratios of workers to pensioners). In the pension literature, the well known 'Aaron-Samuelson' condition states that, in the long run, a country can afford a public pension system that, on average, pays contributors a 'return' equal to the growth of the labour force (in real efficiency units). The question is whether a formula can be found, and implemented automatically, that ensures that this condition is met. Intuitively, it would seem that it is easier to do this in an actuarial-based system in which, for example, accumulated 'points' are indexed to a 'return' based on the growth of the labour force and productivity growth, than in a tax-and-transfer system in which governments can arbitrarily change the generosity of the system as a result of political, as well as economic and demographic, pressures. Actuarial-based systems may therefore be more sustainable in the long run and, given that adjustments are automatic rather than discretionary, provide credibility to the government's revenue-raising function.

These points are not simply of abstract interest. Several countries have in recent years attempted to move their public pension systems closer towards actuarialbased systems in many dimensions whilst maintain tax finance rather than funded provision (and typically keeping the risk-pooling characteristic of public programmes by averaging pensions across differential individual longevity, at least within generations). This trend is most explicit in those countries that introduced what are sometimes termed 'notional account' or (somewhat more misleadingly) 'notional defined contribution' systems of public pension provision, including Sweden, Italy, Poland and Latvia in the mid to late-1990s. In such systems, an earnings-based formula for pension entitlements is replaced by an actuarial-based formula, even though the method of finance remains PAYG. Each individual's contributions to the public programme are recorded and credited with interest each year, according to 
some pre-determined formula. At retirement, the (notionally) accumulated contributions plus interest are converted into a pension on the basis of expected longevity (of that cohort). Other than a move to funding, this represents the most explicit move towards an actuarial-based public pension system.

Given these general issues, the plan of this essay is as follows. Section 2 describes an actuarial-based system and contrasts it with an explicitly redistributive programme. It then delineates four dimensions in which public pension systems diverge from this actuarial benchmark, providing actual illustrations for OECD countries. Section 3 then considers the limited empirical evidence on whether, in practice, deviations from an actuarial basis to the public pension system actually affect household behaviour.

Section 4 then briefly describes some actual reforms in the mid-1990s designed explicitly to move public pension systems towards an actuarial basis. It is too early to use these reforms as 'quasi-experiments' in order to examine household responses to actuarial-based reforms, but it is possible to consider the issue of macroeconomic sustainability in this context - have these countries been able successfully to immunise their public pension systems from macroeconomic fluctuations, or do they still require discretionary budgetary measures in order to keep their PAYG programmes in balance? Finally, Section 5 provides a brief conclusion.

\section{Actuarial-based systems: principles and definitions}

\subsection{Actuarial versus tax-based public pension systems: an illustration}

To examine the distinction between actuarial and non-actuarial based public pension systems, I use the notation of Lindbeck and Persson (2003). Assume that a household lives for two periods with employment income $y$ in the first period, on which a proportional contribution to a pension programme is levied, denoted by $\tau$. Post-tax income can be consumed or saved. In the second period, the household does not work and consumes its saved resources from the first period and a benefit from the pension programme, $b$. Define the market rate of interest as $r$ and consumption as c. The consumption possibilities in the two periods can be written as:

$$
\begin{aligned}
& c_{t+1}^{2}=\left[y_{t}(1-\tau)-c_{t}^{1}\right](1+r)+b_{t+1} \\
& c_{t}^{1} \leq y_{t}(1-\tau)
\end{aligned}
$$


The first equation simply derives from the lifetime budget constraint with no bequests, and states that second period consumption comprises accumulated saving from the first period (plus interest earned at the market rate) and the pension benefit. The second equation states that individuals cannot borrow against their future pensions. If the latter constraint exists, some individuals may be liquidity constrained in the sense that their contributions to the pension programme exceed the amount that they would have saved and may alter the timing of the labour supply and/or consumption. This constraint may bind whether the programme is public or private, and funded or unfunded.

Now assume that the pension programme is 'actuarial-based' in the following senses: (i) an individual's contributions are exactly matched by the programme to his or her individual pension benefits and (ii) contributions 'earn' the market rate of interest $r$. The pension benefit is then:

$$
b_{t+1}=(1+r) \tau y_{t}
$$

Substitution of (3) into (2) yields the revised budget constraint:

$$
c_{t+1}^{2}=\left(y_{t}-c_{t}^{1}\right)(1+r)
$$

We can see that (3) does not include the tax rate $\tau$. Because benefits exactly correspond to contributions plus the market return earned on them, the marginal effective tax on contributors arising from the pension contribution is zero. As the lifetime budget constraint is not affected by this actuarial-based pension system, the individual's savings and labour supply choices are independent of the level of the pension contribution as long as liquidity constraints are not binding.

Now consider a very different scenario. Assume that the public pension system, as before, levies a contribution rate proportional to earnings, $\tau$, but then pays everyone the same benefit, $\bar{b}$ in the second period. Then second period consumption in (1) can be written as:

$$
c_{t+1}^{2}=\left[y_{t}(1-\tau)-c_{t}^{1}\right](1+r)+\bar{b}
$$

Here each individual receive a benefit that is entirely unrelated to his or her contributions - this, I term a 'non-actuarial' programme. In the individual's budget constraint, the effective marginal tax on the individual's work effort is positive at $\tau$. 
The smaller rewards to work can affect both labour supply and saving - the former because the positive tax rate will on various margins induce the household to alter its labour supply so that the marginal disutility of work equals the net-of-tax wage rate (as in Sheshinski, 1978), the latter because the substitutability of pension benefits for other retirement saving depends on the extent to which the pension programme is actuarial-based.

Of course, every public pension system exhibits deviations from an actuarial system, such as floors and ceilings to benefits and contributions, additional allowances for dependants, and so on. In general, it can be said that each programme contains an effective tax component, which lies between 0 and $\bar{\tau}$, the average payroll contribution, depending on how far the programme deviates from an actuarial basis.

\subsection{Is an actuarial-based system possible with Pay-as-you-go finance?}

One question frequently considered in the literature is: can a PAYG-financed public pension system ever be actuarial-based in the sense defined here? In a fully funded pension system, the present value of net wealth invested in the pension plan discounted at the market rate of interest, $r$, equals the present value of liabilities. This constitutes an 'actuarial' programme in the sense described in equations (1) to (3) in Box 2. In a PAYG programme, in contrast, the only requirement for balance is that current receipts equal current outgoings. To write this well-known condition of PAYG equilibrium, write:

$$
n_{t-1} \hat{b}_{t}=\hat{\tau} n_{t} \hat{y}_{t}
$$

where $n$ denotes the number of contributors, with those working at $\mathrm{t}-1$ now retired and receiving pension benefits, so that $n_{t} / n_{t-1}$ is the support ratio of workers to pensioners. As before, $b$ is the pension benefit, $y$ earned income and $\tau$ the contribution rate, with hats denoting averages. Thus $\hat{b} / \hat{y}$ is the average replacement rate, and the equilibrium contribution rate is derived as the average replacement rate divided by the support ratio.

A generational imbalance arises if, given the other parameters of the public pension system, contribution rates are forecast to rise over time in order to satisfy PAYG equilibrium in future years and for future generations. The only sustainable long run 'return' on contributions is where projected $\hat{\tau}$ is constant for given $\hat{b}$ in (5) 
above. As suggested previously, this sustainable return is approximately equal to the sum of the rate of growth of the labour force, $n$, and the rate of growth of real income (productivity), $y$. Call this combined growth rate $g$.

When this growth rate falls short of the rate of return on private investment (that is when $r>g$, which is the condition that an economy is dynamically efficient) a PAYG system cannot be wholly actuarial-based. Again following the notation of Lindbeck and Persson (2003), assume that contributions earn the sustainable 'return' $g$ : i.e.:

$$
b_{t+1}=(1+g) \tau y_{t}
$$

Then substituting into (1), as before, a PAYG system in long run equilibrium gives second period consumption of:

$$
c_{t}^{2}=y_{t}\left[(1-\tau) \frac{r-g}{1+r}-c_{t}^{1}\right](1+r)
$$

If $r>g$ (i.e. the economy is dynamically efficient), there is an average effective tax rate on each successive generation of $\tau(r-g) /(1+r)$ even if the programme has no 'generational imbalance' and even if it is sustainable in the long run. Fenge and Werding (2003) call this difference in pension benefits between a sustainable PAYG system earning $g$ and a funded programme earning $r$ the 'implicit tax' arising from PAYG financing (although, as shown in (4), this need not be the only tax arising from programme design).

\subsection{Intergenerational equity}

Although the only sustainable return on contributions to a public tax-financed pension system in the long run is $g$, actual returns to any generation of retirees can differ from $g$. The first generation in the programme will earn an effective return greater than $g$ simply because they typically receive benefits on retirement without a lifetime of contributions into the system. But variations in programme generosity over time such as the introduction of new benefits, differential indexation procedures, changes in the real value of ceilings and floors and so on, ensure that returns differ generation by generation. I define these departures from the long run sustainable return as departures from generational equity and treat them as divergences from an intergenerational benchmark of an actuarial-based system. 
How large are such departures from generational equity in practice? Do some countries exhibit average returns consistent with $g$ (which will differ from country to country) over time and are there large variations generation by generation? We can examine this by calculating average internal rates of return (IRRs) to contributions for successive generations in OECD countries for a number of retiring generations and see how the returns differ across countries and over time. As a general benchmark, $g$, the sustainable rate of return, is likely to lie in the range of $1 \%$ to $3 \%$. This seems a sensible benchmark if the former averages around $1 \frac{1}{2}$ to $2 \%$ per annum in the long run and the latter depends on both demographic change and changes in economic activity rates (and may therefore be positive or negative).

Disney (2004) calculates average IRRs to public pension contributions for 22 OECD countries in 3 time periods - that is, for generations retiring in the late 1970s and early 1980s and born in 1920 ('Cohort 1920'), the late 1980s and early 1990s ('Cohort 1930') and the late 1990s on ('Cohort 1940'). It is assumed that the first cohort (born 1920) retires with an incomplete earnings record but receives full benefits, and that contribution rates adjust over time to ensure PAYG balance. So higher IRRs derive not from greater generosity of replacement rates (since taxes adjust to finance such benefits on a PAYG basis) but from differences across countries and over time in the average expected length of retirement (i.e. variations in the average retirement age and the average life expectancy at retirement age) and from differences in the generosity of post-retirement indexation of benefits.

Figure 1 reproduces the results of this exercise. Some countries, such as Australia, Canada and New Zealand, exhibit a pattern of IRRs of between 1 to 4\%, declining slightly with later cohorts, reflecting both the generosity of treatment of earlier retiring cohorts and declining labour force growth (i.e. declining $g$ ). Given likely measurement error, such countries are probably close to intergenerational equity, which is our intergenerational benchmark of an actuarial-based system. A few countries, such as Ireland, the United Kingdom and the United States, actually exhibit IRRS that are probably below a likely value of $g$. It is of interest to note that both these groups of countries are generally associated with an Anglo-Saxon (sometimes termed 'Beveridge') form of social security programme in which benefits are generally not related to contributions and are floor-based, and in which there is substantial private provision of pension benefits. 
Now consider many of the other countries in Figure 1, notably those from continental Europe that operate a 'Bismarck' form of social security. In many of these, IRRs are much higher but show a distinct pattern of decline for later cohorts. Although I have not calculated $g$ country-by-country (and many of these countries did exhibit significant labour force growth in the 1960s and 1970s), IRRs of greater than $5 \%$ are unlikely to be sustainable in the long run. In other words, these are mostly countries that are not actuarial-based (in an intergenerational sense) and where the requirements of PAYG equilibrium from equation (5) above have required rising contribution rates over time. ${ }^{2}$ It is no coincidence that, in many of these countries, there is strong pressure to introduce a stronger actuarial basis to the public pension system.

\subsection{Actuarial fairness}

Implicit in the earlier discussion of an actuarial-based system was another dimension of system design. This concerns differences in benefits relative to contributions within generations, that is, the intragenerational features of a public pension system. Compare a programme that pays benefits to all proportional to contributions (as in equations (2) and (3) above) with a programme that pays a fixed pension benefit to all, as in equation (4). The latter exhibits strong within-generation redistribution, not just by risk-pooling across different classes of longevity risk (which is intrinsic to social insurance programmes) but also because the benefit formula gives greater replacement rates to households with lower lifetime income. ${ }^{3}$ I define a programme that broadly matches benefits to contributions within a generation as an actuarially fair programme, whereas a programme such as that depicted in (4) departs significantly from actuarially fairness ('equity' and 'fairness' here should not be treated as constituting any social welfare judgements but merely as providing benchmarks against which to judge an actuarial-based programme).

\footnotetext{
2 In fact a number of these countries, such as Greece and Italy, have consistently run deficits on their public pension system, financed out of general revenue. Since the incidence of general taxation may differ from a fully-financed contribution-based system, this calculation may slightly understate IRRs in those countries.

3 Since mortality is generally negatively related to lifetime wealth, these two facets of the programme may offset one another.
} 
How large are these departures from 'actuarial fairness'? As stated in Section 1 , every programme in practice contains departures from actuarial fairness in this sense. Disney (2004) uses data from Blöndal and Scarpetta (1998) to illustrate some stylised calculations for the same 'generations', here defined by the date at which they are aged 55. Blöndal and Scarpetta report expected pension replacement rates for four categories of 55 year old contributors: single people and couples, on average earnings and at $66 \%$ of average earnings. To give an example from their data, the 1995 figures for replacement rates for Belgium are singles at mean earnings: $60 \%$, at $66 \%$ of mean earnings: 60\%; couples at mean earnings: $75 \%$, at $66 \%$ of mean earnings: $75 \%$. Clearly in one dimension there is approximate actuarial fairness (earnings level) but not in another (singles v. couples). Compare this with Australia where the respective replacement rates are $37 \%, 24 \%, 62 \%$ and $41 \%$, and where there are departures in both dimensions.

A useful quantitative indicator of the relevant differences can be computed as follows. If the four Blöndal and Scarpetta expected replacement rates are identical for each country-time observation, the programme is approximately actuarially fair (in this dimension). If the rates vary, then the coefficient of variation of the replacement rates gives an approximate measure of the departure from actuarial fairness in each country and time period (the normalisation does not affect the ranking: a similar ordering would occur if, say, the mean square error was used). Figure 2 illustrates these calculated 'tax components' for each country and each year.

Again, what is striking is the difference between 'Beveridge' and 'Bismarck' regimes: the former tends (by design) to exhibit significant departures from 'actuarial fairness', the latter is much closer to this benchmark of an actuarial-based programme (note, however, that we are calculating the indicator from four stylised types of households - the more household types that are distinguished, the more departures from 'fairness' would be uncovered, without this being likely to affect these rankings). By the criterion discussed in Section 1, therefore, 'Beveridge' or AngloSaxon-type programmes exhibit a high tax component, although generally not suffering the ever-rising contribution rates exhibited by 'Bismarck' programmes arising from departures from what I termed 'intergenerational equity' (the Netherlands appears to be one exception to this general rule). 


\subsection{Actuarial neutrality}

A final criterion for judging the actuarial basis of a public pension system arises from the incentives to retire or to remain in the workforce late in the working life. Intrinsically, the retirement decision should be forward-looking - examining the opportunity cost of continuing to work relative to current and expected benefits (which may themselves be affected by postponing the retirement decision) after the age at which the individual is first entitled to a public pension. In OECD terminology this is commonly described as the (marginal) implicit tax rate on (continued) employment (not to be confused with the 'implicit tax rate' arising from PAYG financing described in Section 2.2 above). This calculated tax rate can be greater, less than or equal to zero. A benchmark for the retirement decision is where this implicit tax rate is zero and the individual's budget constraint gives an equal value to continuing to work and retiring now (in which case the retirement decision will wholly be determined by preferences and expected individual mortality risk). I term this actuarial benchmark where retirement age is flexible as actuarial neutrality.

To illustrate this, define the expected effective tax rate, $m$, from one more year's work at age $a$ at some time $t$ as the marginal implicit tax rate $=m(t, a)=$ $-\Delta p(t, a) / w\left(1-x_{w}\right)(t, a)$ where the change in pension wealth at age $a$ is $\Delta p$, the wage is $w$, and both are defined net of other personal taxes, $x$. Clearly the sign of $m$ depends on the sign of $\Delta p$.

If we further define $s_{i}$ as the individual probability of surviving from one period to the next, then $\Delta p=\sum_{i=a+1}^{\infty} s_{i}\left[p_{a+i}-p_{a}\right]\left(1-x_{p}\right)\left(1+\delta_{i}\right)^{-1}-\left[c_{a}+p_{a}\left(1-x_{p}\right)\right]$ where $c$ is the contribution rate and $\delta_{i}$ is the individual's discount rate. The first term represents the increased prospective pension benefit stream $\times$ the probability of surviving from $a$ to $a+1$ (parameter $s$ ), and the second the costs of continuing to work as the contribution plus foregone pension at that age. When these are equal $\Delta p$ is zero and so is $m$.

Note that the marginal implicit tax rate does not directly determine the retirement decision. It defines the budget constraint for every future date at which there is a choice between work and retirement ( $p_{a}$ gives the 'wealth effect', as a current annuity value). Within the 'window' during which the retirement date can be chosen, the pension accrual $\Delta p$ will depend on the benefit formula (for example, 
whether an extra year of contributions 'count' towards benefits) as well as the possibility of deferring benefits, and at what rate. And the individual's decision as to when to retire will depend on the distributions of $s$ and $\delta$ across individuals as well as accumulated wealth.

What do these marginal implicit tax rates on continued work look like in practice? Table 1 utilises data from Blöndal and Scarpetta (1998) to examine whether postponing retirement increases prospective public pension wealth. A positive sign indicates that an incentive exists, zero indicates 'actuarial neutrality' (at the assumed discount rate of $3 \%$ ) and a negative sign indicates that there is a disincentive to continue in work. In almost all cases, the sign is negative and has risen between 1967 and 1995 despite some efforts to reform public pension systems to encourage people to retire later, the reason being that life expectancy has tended to rise faster than the rate at which incentives to retire early have been reduced. Note, too, that these calculations ignore other early retirement 'routes' in the public pension welfare programme such as disability pensions. When these, too, are taken into account, the disincentives to postpone retirement are correspondingly increased (Gruber and Wise, 1999).

\section{Measuring the incentives effects of deviations from actuarial-based public pension systems}

The introduction to this paper suggested that public pension systems depart from actuarial-based systems in a number of respects. These include the 'implicit tax' arising from PAYG funding, and departures from what I termed intergenerational neutrality, actuarial fairness and actuarial neutrality respectively. In principle, all these deviations from an actuarial-based system affect household behaviour, notably in the terms of labour saving and incentives to save. But how important are these effects in practice and do they suggest that policies to move programmes closer to an actuarial basis will generate significant efficiency gains? And if so, what are the most relevant margins?

The first issue: the implicit tax implied by PAYG financing where $r>g$, has been extensively discussed. Feldstein (1996) is the seminal account of the welfare losses arising from PAYG financing rather than full funding of pension programmes. The huge literature that has arisen on this issue tends to focus on two issues: how 
large is the disparity between $r$ (the 'return' on contributions to a funded programme) and $g$ (the 'return' on contributions to a tax-financed programme), and what is the magnitude of the transition cost in moving from PAYG financing to full funding? These issues are discussed elsewhere in this volume.

Issues arising from departures from 'intergenerational equity' and 'actuarial fairness' have been much less extensively discussed. Nevertheless these might be significant: as mentioned in the introduction, to the extent that public pension system are perceived as having a substantial 'tax component' (and look less like mandatory retirement saving programmes) there might be impacts on both labour supply and saving behaviour.

In testing this general hypothesis, one possibility is to ask people about what type of pension programme they would prefer to save in (as in Boeri, Börsch-Supan and Tabellini, 2001) but such studies only cover a limited number of countries and the interpretation of responses is not always straightforward. An alternative is to construct some form of econometric test, in which an economic variable such as the economic activity rate or the saving rate is linked to cross-country or temporal differences in the design of the public pension system.

Disney (2004) undertakes a panel analysis of economic activity rates of different sex and age groups across OECD countries, in which these activity rates are linked to macroeconomic variables and institutional indicators - some of which are measures of the extent to which public pension systems are actuarial-based as described in Figures 1 and 2. He shows that economic activity rates of women of different ages are typically higher (other things being equal) where the programme has a lower intragenerational tax component (as measured by the variable in Figure 2), where the internal rate of return to pension contributions is higher (see Figure 1), and where the overall generosity of the programme (as measured by the expected pension replacement rate) is lower. However, for men, there are no significant effects of these indicators on economic activity.

Does this imply that countries should move closer to an actuarial-based programme if they want to achieve higher employment growth? For 'Beveridge'-type programmes, these results give conflicting signals. On the one hand, such programmes deviate substantially from 'actuarial fairness' (Figure 2). On the other 
hand, 'floor-based' programmes of this type typically have a low absolute tax burden. These effects may offset one another. Conversely, 'Bismarck'-type programmes typically depart from intergenerational equity, from actuarial neutrality (in terms of retirement incentives) and also have a higher tax cost given high replacement rates. These factors may slow down employment growth in such countries and give rise to pressure for an even closer link between contributions and entitlements.

The link between type of public pension system and savings rates has not, to my knowledge, been analysed. The seminal work of Feldstein (1974) on the impact of public pension wealth on household saving has been followed up on a crosscountry basis by a number of studies (summarised in Disney, 2000a). These suggest that more generous public pension systems tend to crowd out private retirement saving both at a macro level (i.e. cross country) and across households, the latter exploiting differential changes in pension wealth across households arising from pension reforms (Attanasio and Brugiavini, 2003; Attanasio and Rohwedder, 2003). However, no paper has as yet linked these offset effects to the differential design of pension programmes across countries or over time periods. This issue seems important in programmes which are depart significantly from actuarial fairness, and in particular where pension entitlements are income or asset-tested, which might be expected to have a significant impact on retirement saving (Disney and Emmerson, 2004).

Finally, there is robust evidence that departures from actuarial neutrality in terms of retirement incentives may have adverse effects on activity rates of older people. Blöndal and Scarpetta $(1997,1998)$ use cross-country fixed effect models to examine the effect of a host of factors on participation rates of older workers. They show that "a 10 percentage points reduction in the implicit tax on continued work from 55 to 65 years of age would lead to an increase in participation rates among older males of about 1.8 percentage points" with the fall between 1967 and 1995 (see Table 1) of pension wealth accruals from deferred retirement accounting for substantial drops in labour force participation in Finland, Italy, the Netherlands and Portugal (1998, p. 41).

In similar vein, the country studies in Gruber and Wise (1999) calculate implicit tax rates on marginal earnings at the first date at which retirement is possible arising from departures from actuarial neutrality in public pension and welfare 
programmes, along the lines described in Section 2.5 above. They establish that there is a strong positive relationship across countries in the mid-1990s between their implicit tax rates cumulated from the first eligible age of retirement through to age 69 (which they term the tax force) and the extent of their underutilisation of the workforce, as measured by economic inactivity rates in the age range 55 to 65 (see Figure 17, pp.32-34). In later microeconometric analyses (Gruber and Wise, 2002), the authors confirm that these incentive effects have a major explanatory role in models of retirement based on household data.

\section{Actuarial-based reforms of public pension systems}

Although the literature does not give a clear-cut answer as to whether actuarial-based programmes are welfare-improving, the late 1990s saw several wellpublicised pension reforms that introduced 'notional account' (also known as 'notional defined contribution' - NDC) systems as one solution to the financing problem associated with existing public defined benefit programmes. The two countries that provided the impetus for these reforms were Sweden and Italy. The reform proposal in the Sweden also precipitated two 'test bed' reforms in Latvia and Poland - the former almost explicitly a trial run for the Swedish reform, the latter containing a number of additional features. The Italian 'Dini' reform of 1995, which implemented a transition to an actuarial-based system of individual accounts followed a more standard 'parametric' reform of the defined benefit pension plan in 1992 that had attempted to cut back the burgeoning deficit on the pension programme.

These reforms are briefly described here. Since the reforms largely eschew greater funding (although small funded components form a part, or an ideal future part, of each reform), they do not handle the 'implicit tax' issue arising from PAYG finance (see Section 2.2 above). Therefore the reforms are primarily designed to introduce the other components of an actuarial basis described in Sections 2.3 to 2.5 greater intergenerational equity, actuarial fairness and actuarial neutrality.

Of course, reforms of this kind can be introduced without recourse to the whole NA/NDC apparatus of individual accounts - for example, many countries have attempted to improve retirement incentives in the late 1990 s so as to reduce the marginal implicit tax on postponing retirement (i.e. towards greater actuarial neutrality). More strikingly, the 2004 public pension reform in Germany constructs 
an aggregate formula that indexes benefits to earnings growth $(g)$ and a 'sustainability formula' $(n)$ without introducing individual accounts (Börsch-Supan and Wilkie, 2003). Moreover, despite their 'defined contribution' name, NDCs are primarily reformed defined benefit systems where pension accruals and indexation procedures are formula-based. Nevertheless the 'individualisation' of the pension account is presumably designed to promote a different individual patterns of incentives, perhaps reflecting the modern trend in behavioural economics that suggests that saving and consumption decisions of households are partly influenced by the form in which saving opportunities are presented.

\subsection{Italy}

The Italian reform of 1995 (implemented in January 1996) introduced a new public pension system that made pension entitlements conditional on the accumulated sum of payments paid, rather than on age or years of service (for descriptions, see Castellino and Fornero, 2001; Brugiavini and Fornero, 2001; Gronchi and Nisticò, 2003). Contributions are notionally accumulated in individual accounts that are revalued in line with a moving average of GDP growth. Since contributions are approximately linearly proportional to earnings, this feature moves the system closer to 'actuarial fairness' (although in practice there is a benefit floor and other milder non-linearities) and, with the revaluations linked to the PAYG feasible long run rate of return, there is a procedure designed to mimic 'intergenerational equity'.

The annuity value of the contribution balance at retirement is then calculated as a product of this revaluation and a 'transformation coefficient' conditional on the age of retirement. These 'transformation coefficients' are the products of what would normally be called annuity factors - the rate of pension conditional on life expectancy at each age of retirement within a cohort - and are therefore designed to move the programme closer to 'actuarial neutrality'. These values are tabulated in advance. Once in payment, pensions were to be indexed to prices (although initially they were indexed to earnings).

The Italian reform therefore illustrates the two key features of this type of reform: that it is formula-driven (and the formula, and it values, are public knowledge, whether or not fully understood by the public) and that the public pension system is presented as a programme of individual accounts (although still tax-financed). 
There are several features of the Italian reform, however, that enhance the scope for discretionary changes and political manipulation. First, there is still a window of retirement ages (currently 57 to 65), which is to be reconsidered at regular intervals. Of course, with increasing longevity, the age of first retirement has to be raised regularly on the basis of actuarial projections of longevity of future generations. This retirement age is potentially (and has proved in practice to be) a source of continued political negotiation.

Second, there is an extremely long transition period in moving from the existing 'redistributive' system to the new programme. New labour market entrants from 1996 onwards belonged wholly to the new system, those with between 1 and 18 years of contributions in 1996 will retire with a mixture of benefits from the new and the old systems, and those with 18 years or more contributions will retire under the rules of the 'old' system. This means that the system will not be in 'steady state' until well into the 2040s, which gives plenty of scope for subsequent political manipulation. Indeed, in the transition, the programme remains out of fiscal balance since non-contributory tax revenues are used to augment contributions in order to finance some of the existing ongoing liabilities. Finally, the programme still contains features, such as a minimum pension, that provide a departure from an actuarial basis within generations.

Inevitably, given an existing institutional setting, it is difficult to introduce a 'pure' actuarial-based programme, even allowing for continued tax-based finance. The major defence of the Italian reform was that it moved Italy away from a trend towards a deficit-financed unsustainable public programme that had only been halted by the $a d$ hoc and therefore potentially reversible 1992 reforms. Nevertheless some hostages to fortune remain in the Italian programme - notably the long transition period, the failure to index retirement age and the minimum pension. Current (2004) measures to eradicate some of these features, notably to raise the retirement age, seem likely to be implemented only with concessions that might erode some other actuarialbased features of the post-1995 programme.

\subsection{Italy}

The Swedish pension reform was initiated in 1994 but the majority of the required legislation was not passed until 1998 (Palmer, 2000). Like Italy, the new programme devises a set of individual accounts, one novelty being that a small 
proportion of the contribution ( $2 \%$ of $18.5 \%$ ) will be invested in a funded component, the rest being put into the PAYG programme. The accounts are indexed to earnings growth (so there is no allowance for changes in the labour force growth rate - which may be positive or negative) but there is some allowance for changes in the growth rate of the labour force in the post-retirement indexation of benefits which, instead of being indexed to prices or earnings growth, are indexed by a formula which takes account of any deviation of real wage growth from a growth 'norm' (set at 1.6\% annum). ${ }^{4}$ As with Italy, there is a formula that links annuity factors at retirement to published life expectancy tables.

As with Italy, the system is introduced gradually but retrospectively, so that individuals born between 1938 and 1953 (i.e. aged 45 to 60 in 1998) accrue rights under a mixture of the old and new rules. For those aged 45 and below, all new rights are accrued under the new system. So the transition to the 'steady state' is much faster than in Italy. A major departure from 'actuarial fairness', to be expected in the social welfareist environment of Scandinavia, is that individuals can accumulate notional contributions to the new plan from periods of economic inactivity: for women bringing up young children, spells of unemployment, sickness and disability, periods of military conscription and post-school education.

\subsection{Latvia and Poland}

Although the reforms in these countries are also of interest, they can be summarised given that many of their features have already been encountered. The Latvian reform was introduced in 1995-96 and bears all the hallmarks of a 'test bed' for the Swedish reform (see Fox and Palmer, 1999). It is therefore very similar to Sweden's bar two features of importance. First, the accounts are revalued in line with, not the growth of earnings or GDP, but the growth of the contribution base. Whilst this is technically, a 'better' measure of the underlying PAYG 'feasible' rate of $g$, it is inevitably the case that the contribution base is highly volatile in a transition economy such as Latvia (this is illustrated in Disney, 1999, Figure 1). Consequently, the value of notional accounts in Latvia in the period after 1995 fluctuated

\footnotetext{
4 This example is from Sundén (1998). Suppose inflation is $2 \%$ p.a. and actual real wage growth is $0.5 \%$ p.a.. Then actual indexation is $(2-(1.6-0.5))=0.9 \%$ p.a. Thus slower real wage growth than average GDP growth is reflected in a fall in the real value of the pension. This is an alternative to the indexation of the account to real GDP growth (Italy) or real earnings growth plus a 'sustainability formula', as in the 2004 German reform.
} 
significantly (e.g. $\pm 15-20 \%$ from year-to-year) and on a par with fluctuations in the values of funded accounts. If one rationale for not funding pensions is the lower volatility of accumulated funds, indexation procedures of this type are not helpful. Secondly, and also inevitably in a transition economy, the minimum pension remains very important and its value will probably determine pension values for a long time to come. $^{5}$

The Polish reform, introduced in 1999, has several similar features to that of Latvia, with the addition of a funded component which is, in some respects, it's most interesting feature (for details, see Chlon, Góra and Rutkowski, 1999). Again, the idea is that in the long run, the PAYG 'pillar' will be comprised of individual accounts, indexed to the growth of the real wage bill but with a significant and relatively generous minimum pension. Again, there are carrots and sticks designed to persuade people to defer taking their pension: a significant rise in the minimum pension age and deferral rates (annuity factors) that broadly reflect differences life expectancies at different retirement ages. Pensions in payment will be indexed to price inflation, unless real wages are falling when they will be indexed to nominal wage growth. A second pillar of individual funded accounts is introduced, with a much greater share of the total contribution than in Sweden. One's intuition is that, in the long run, the NA/NDC aspect of the programme in Poland is of less significance compared to what happens to (i) the value of the minimum PAYG pension (ii) the retirement age and (iii) the value of individual funded accounts. In this sense the programme is not as 'full blooded' a shift to a tax-financed actuarial-based programme as the other countries described here.

\section{Can an actuarial-based programme guarantee macroeconomic sustainability?}

One of the claims most often advanced for a shift to an actuarial-based programme is that it introduces automatic macroeconomic stability to the programme. One of the major problems of existing defined benefit public programmes is that, as populations age, and without the types of adjustment mechanisms described here, there is an unerring tendency towards higher pension costs as a share of GDP over

\footnotetext{
5 A personal view is that it is undesirable to use transition economies as 'test beds' for 'extreme' reforms - whether shifts to fully actuarial-based programmes, or indeed fully privatised programmes. In this sense, the 'multipillar' strategy seems a better option.
} 
time. This is the sense in which OECD pension programmes are commonly seen to be in 'crisis' (Disney, 2000b).

In the long run it is generally agreed that linking the 'return' on contributions in a public programme to $g$, whether done through a macroeconomic formula as in Germany or by individual accounts, should arrest this tendency to rising costs although it is arguable (at least in the Italian context) that a retrenchment in pension costs is required and not just a cap on their growth. However, advocates of actuarialbased programmes sometimes go beyond this general statement to assert that implementation of these regimes removes the need for even short term discretionary stabilisation of the programme. Is this correct?

The essential problem can be simply stated. Linking benefit entitlements to $g$ is treating the programme, by analogy, as if it were a funded programme (as in the illustrations given in equations (1) to (4) in this essay) albeit earning a lower return. In a funded programme, contributions 'earn' $r$ and the 'implicit tax' arising from PAYG finance is $(r-g)$, as described above. But the analogy, while attractive, is misleading. PAYG finance is not like funding, and the equilibrium requirement is that current pension expenditure equals current tax receipts. In a static environment, or where all variables perpetually grow at their steady state values, a rule can be implemented that rules out the need for discretionary actions to restore fiscal balance, and many 'proofs' of propositions concerning actuarial-based systems use models (for example, propositions from comparative statics) of this type. The picture is quite different where pension programmes face macroeconomic and demographic 'shocks'.

Faced with shocks, what formula, if any could guarantee short run stability? Valdés-Prieto (2000) considers the issue formally and comprehensively, but the results are fairly intuitive. The issue partly depends on the timing of new information, and on whether the shocks are primarily macroeconomic (that is arising from earnings, productivity or labour force growth, or from inflation) or demographic (arising from changes in longevity, assuming that the impact of fertility rate changes can be predicted and that changes in net migration are too small to 'matter').

If the shocks only come from the macroeconomic side, the first possibility is to index claims on the system to aggregate contribution revenues. This would 'work' insofar as it is the dynamic analogy to equation (5) for PAYG equilibrium. Since the 
right hand side of that equation is total contribution revenue, and since the number of pensioners is known from the size of the past workforces, a formula that automatically indexed interest on accumulated contributions as well as pension benefits to changes in contribution revenue would indeed automatically stabilise the programme - it is like first differencing the formula and netting out a constant tax rate. Unfortunately, changes in contribution revenue are generally an outcome variable that cannot be observed in time to alter announced interest rates on accumulated contributions and to index pension benefits. If lagged contribution revenues are used, then ex post adjustments of interest on accumulated contributions will never guarantee actuarial balance. However, so long as any discrepancies between changes in contribution revenues are serially uncorrelated and relatively small, and the PAYG programme retains a small reserve fund, such fluctuations can be absorbed (this is in fact how PAYG programmes operate in practice, subject to the major constraint that they are pre-committed to a certain level of benefits - here, this would be replaced by a formula that targeted the benefit level on outcomes in terms of contribution revenue).

Valdés-Prieto shows that other indexation formulae do not have this property. Intuitively, we can see that from equation (5) above that indexing benefits to the growth of covered wages, as in Sweden, will not suffice (although as the earlier footnote suggested, Sweden then has a balancing formula in determining the postretirement indexation of benefits). Indexing contributions and the pension benefit to the growth of the wage bill, as in most of the other countries that have introduced notional account-type programmes, is more intuitive. However, in the Valdés-Prieto set-up of the problem, the relationship between the growth of the wage bill and the indexation of pension rights would be proportional but not unitary (ibid p.403) since the outcome also depends on the contribution rate. In steady state growth (constant contribution rate), indexing to the covered wage bill does ensure macroeconomic stability, but not if the contribution rate is time-varying.

These stabilisation measures may or may not 'work' in the face of macroeconomic shocks. But if there are also demographic shocks, a second instrument is needed, which adjusts the annuity rates at retirement to changes in expected longevity. The concern here is not that there are difficulties in doing this (private annuity markets are supposed to handle exactly this sort of problem) but that 
government actuaries seem to have rather a poor record in forecasting aggregate longevity changes (Disney, 2000b).

Looking at individual countries that have moved towards actuarial-based programmes, these problems of automatic stabilisation have not been completely solved, although it is at least arguable that the presence of some stabilisers are better than none. Sweden and Germany have attempted, or are attempting, to introduce demographic adjustments to either benefits or retirement ages that handle demographic shocks. It is not clear that this has been done in Italy, other than in a somewhat ad hoc way by raising retirement ages. On the other hand, indexing pension claims to GDP growth or the growth of the wage bill, which has taken place in all NA-type countries except Sweden, is probably closer to what is required for macroeconomic stabilisation than Sweden which indexes to covered earnings and therefore is still required to make periodic discretionary adjustments to programme finances in order to maintain PAYG equilibrium.

\section{Conclusion}

This essay has considered actuarial-based public pension systems - that is, tax-financed public programmes that, in one way or another, impose contributory requirements or other design mechanisms that imitate, however imperfectly, a funded retirement saving programme. It considered some rationalisations for such procedures - primarily enhanced revenue-raising capacity, elimination of perceived tax distortions to labour supply and saving, and built-in macroeconomic stabilisation, especially in the face of adverse demographic shocks and the perceived financing crisis in several OECD countries.

The dimensions in which PAYG programmes depart from this actuarial basis were then considered (Section 2). The fundamental point is that a PAYG programme can never 'earn' the same return on contributions to the programme as a funded system when an economy is dynamically efficient. However, this basic point should not be laboured to the point of excluding other deviations from an actuarial-based programme, which I labelled departures from intergenerational equity, actuarial fairness and actuarial neutrality. I then considered the importance of these factors empirically, using illustrations from OECD countries. The essay then considered whether these deviations from actuarial-based programmes actually 'mattered', in the 
sense of causing observable changes in household behaviour. Given that the issues have been discussed at great length at a theoretical level, it is interesting (but perhaps symptomatic of modern economics) to note how few empirical studies there were that attempted to address this practical issue. However such studies as exist were discussed in Section 3.

Section 4 then considered 'Notional Account' or 'Notional Defined Contribution' (NDC) reforms in practice in a number of other countries - how they worked and the extent to which they had successfully handled the intrinsic components of actuarial-based programmes described in Section 2. Finally, the last section considered the important issue of whether switching to actuarial-based pension regimes allows countries both to absorb long run changes and short run 'shocks' to macroeconomic and demographic variables.

As with other generic reform packages, NA or NDC-type reforms are not a 'magic wand' to solve the problems of financing pensions. They provide some degree of transparency, a degree of stability, and avoid some of the issues involved in moving towards greater pre-funding. More generally, shifts to actuarial-based programmes can improve incentives. However such programmes inherently reduce the redistributive capacity of social welfare policy, which may or may not be an objective of government. And whilst they add an important transparency to the programme in informing contributors of what their pensions will be worth, removing this in part from the political process, they may have the harmful effect of persuading contributors that, somehow, their pension 'rights' are no longer dependent on the willingness-to-pay of future taxpayers. Although funded programmes are themselves not immune from the interference of governments, it is important not to lose sight of the fact that actuarial-based programmes are, ultimately, tax-and-transfer programmes and dependent on the intergenerational solidarity of taxpayers. Coping with ageing populations remains a challenge to many countries whatever the pension programme that is chosen. 


\section{References}

Attanasio, O., and Brugiavini A. (2003), 'Social security and households' saving', Quarterly Journal of Economics 118, 1075-119.

Attanasio, O. and Rohwedder, S. (2003), 'Pension Wealth and Household Saving: Evidence from Pension Reforms in the U.K.', American Economic Review, 93(5), 1499-1521.

Blöndal, S. and Scarpetta, S. (1997) 'Early retirement in OECD countries: The role of social security systems', OECD Economic Studies, No. 29, Paris.

Blöndal, S. and Scarpetta, S. (1998) 'The retirement decisions in OECD countries', OECD Economics Department Working Paper, No. 202, Paris.

Boeri, T., Börsch-Supan, A. and Tabellini, G. (2001) 'Would you like to shrink the welfare state? The opinions of European citizens', Economic Policy, Vol. 16, April, 7-50.

Börsch-Supan, A. and Wilkie, C. (2003) 'The German public pension system: How it was, how it will be', mimeo, Mannheim Research Institute for the Economics of Ageing, Mannheim, Germany.

Brugiavini, A. and Fornero, E. (2001) 'Pension provision in Italy', in R. Disney and P. Johnson (eds) Pension Systems and Retirement Incomes in OECD Countries, Edward Elgar: Cheltenham.

Chlon, A., Góra, M. and Rutkowski, M. (1999) 'Shaping pension reform in Poland: security through diversity', World Bank SP Discussion Paper No. 9923, Washington D.C.

Disney, R. (1999) 'Notional accounts as a pension reform strategy: An evaluation', World Bank SP Discussion Paper No. 9928, Washington D.C.

Disney, R. (2000a) 'Declining public pensions in an era of demographic ageing: Will private provision fill the gap?' European Economic Review, 44, 4-6, 957-973.

Disney, R. (2000b) 'Crises in OECD public pension programmes: what are the reform options?' Economic Journal Features, 110, February, F1-F23.

Disney, R. (2004) 'Are contributions to public pension programmes a tax on employment?' Economic Policy, 39, July, 267-311.

Disney, R. and Emmerson, C. (2004) 'Public pension reform in the United Kingdom: what effect on the financial well being of current and future pensioners?', mimeo, Institute for Fiscal Studies: London.

Feldstein, M. (1974) 'Social security, induced retirement and aggregate capital accumulation', Journal of Political Economy, 82 (5), 75-95.

Feldstein, M. (1996) 'The missing piece in policy analysis: social security reform', American Economic Review Papers and Proceedings, 86, May, 1-14.

Fenge, R. and Werding, M. (2003) 'Ageing and fiscal imbalances across generations: Concepts of measurement', CESifo Working Paper No. 842, January.

Fox, L. and Palmer, E. (1999) 'Latvian pension reform', World Bank SP Discussion Paper No. 9922, Washington D.C. 
Fornero, E. and Castellino, O. (2001) La Riforma del Sistema Previdenziale Italiano, I Mulino Studi e Richerche, Bologna.

Gronchi, E. and Nisticò, C. (2003) Fair and sustainable pay-as-you-go pension systems: Theoretical models and practical realizations, Consiglio Nazionale dell'Economia e del Lavoro, Rome.

Gruber, J. and Wise, D. (1999) (eds) Social Security and Retirement around the World, Chicago: Chicago UP for National Bureau of Economic Research.

Gruber, J. and Wise, D. (2002) (eds) Social Security and Retirement around the World, Micro-estimation, Chicago: Chicago UP for National Bureau of Economic Research.

Lindbeck, A. and Persson, T. (2003) 'The gains from pension reform', Journal of Economic Literature, XLI, March, 74-112.

Palmer, E. (2000) 'The Swedish pension reform - framework and issues', World Bank SP Discussion Paper No. 0012, Washington D.C.

Sheshinski, E. (1978) 'A model of social security and retirement decisions', Journal of Public Economics, 10, 337-360.

Sundén, A. (1998) 'The Swedish pension reform', mimeo, Federal Reserve Board, April.

Valdés-Prieto, A. (2000) 'The financial stability of notional account pensions', Scandinavian Journal of Economics, 102 (3). 395-417. 
Table 1

Cumulated pension wealth accruals for single people on average earnings

\begin{tabular}{|l|c|c|c|c|}
\hline & Postponing retirement 55 to 64 & \multicolumn{2}{|c|}{ Postponing retirement 55 to 69 } \\
\hline & 1967 & 1995 & 1967 & 1995 \\
\hline United States & -0.8 & -1.2 & -1.9 & -2.5 \\
Japan & -1.0 & -2.8 & -2.1 & -3.9 \\
Germany & -0.4 & -1.4 & -2.9 & -3.4 \\
France & -0.2 & -1.4 & -1.2 & -3.7 \\
Italy & -3.0 & -7.9 & -4.5 & -11.8 \\
United Kingdom & -0.6 & -0.5 & -1.4 & -1.5 \\
Canada & 1.5 & -0.6 & -0.1 & -1.6 \\
& & & & \\
Australia & 0 & 0 & -0.8 & -0.9 \\
Austria & -3.1 & -3.4 & -6.5 & -7.0 \\
Belgium & 0.2 & -2.3 & -2.3 & -5.0 \\
Denmark & 0 & 0 & -0.6 & -0.8 \\
Finland & 0 & -2.2 & -1.3 & -4.9 \\
Ireland & -0.5 & -1.4 & -0.6 & -2.6 \\
Netherlands & -0.9 & -1.3 & -2.3 & -2.9 \\
New Zealand & 0 & -0.9 & -0.5 & -2.3 \\
Norway & -0.3 & -1.5 & -0.3 & -3.3 \\
Portugal & -0.5 & -0.4 & -3.8 & -3.7 \\
Spain &.. & -1.4 & -.4 & -5.9 \\
Sweden & 0.9 & -1.8 & 0 & -3.3 \\
Switzerland & 0.2 & 0 & -0.7 & -1.5 \\
\hline
\end{tabular}

Source: Blöndal and Scarpetta (1998), Table III.6 
Figure 1

Internal rates of return (IRRs) to pension contributions, by country and cohort (generation)
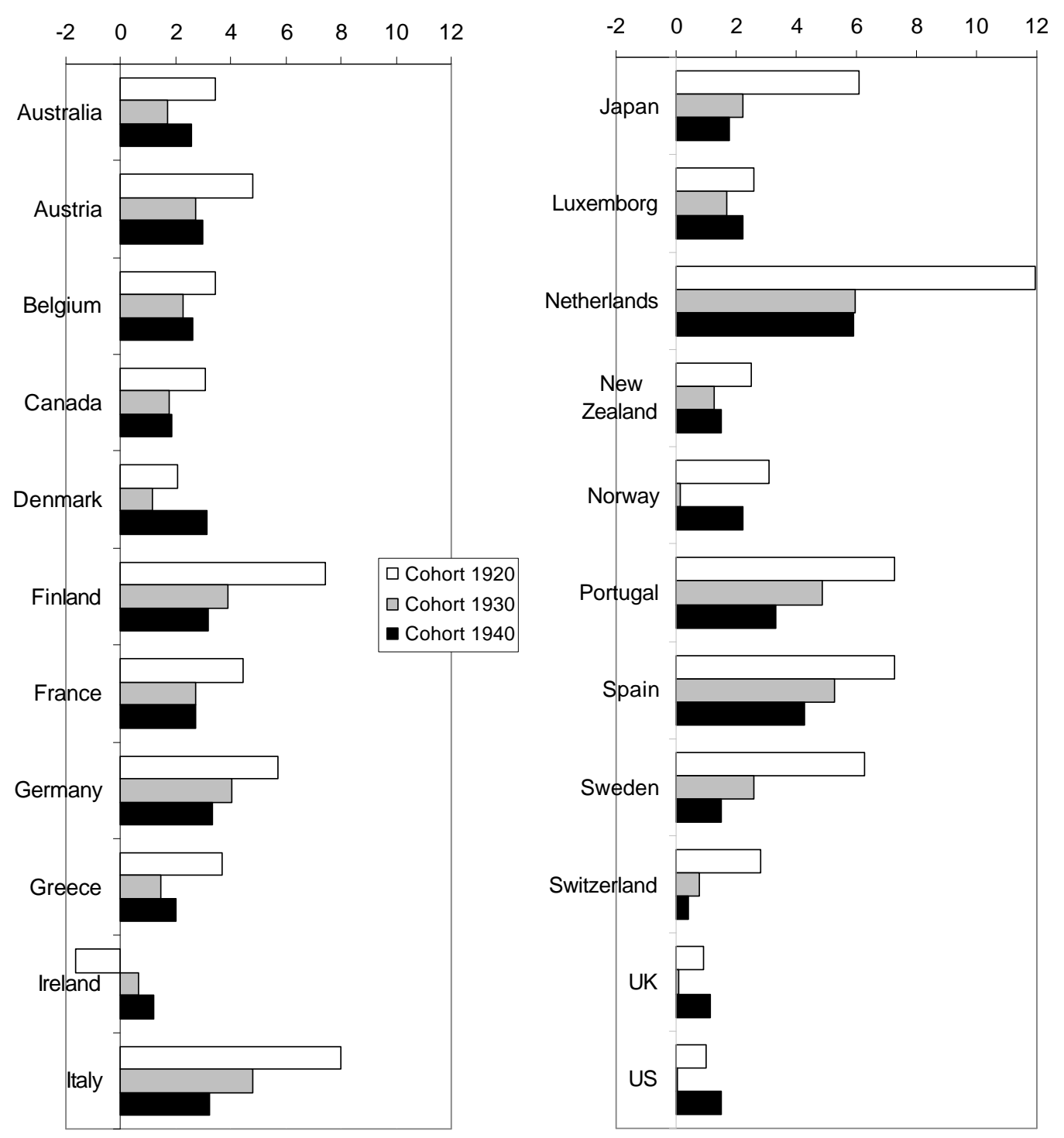

Source: Disney (2004) Figure 1. 


\section{Figure 2}

\section{Effective tax components, from inter-household} variations in replacement rates
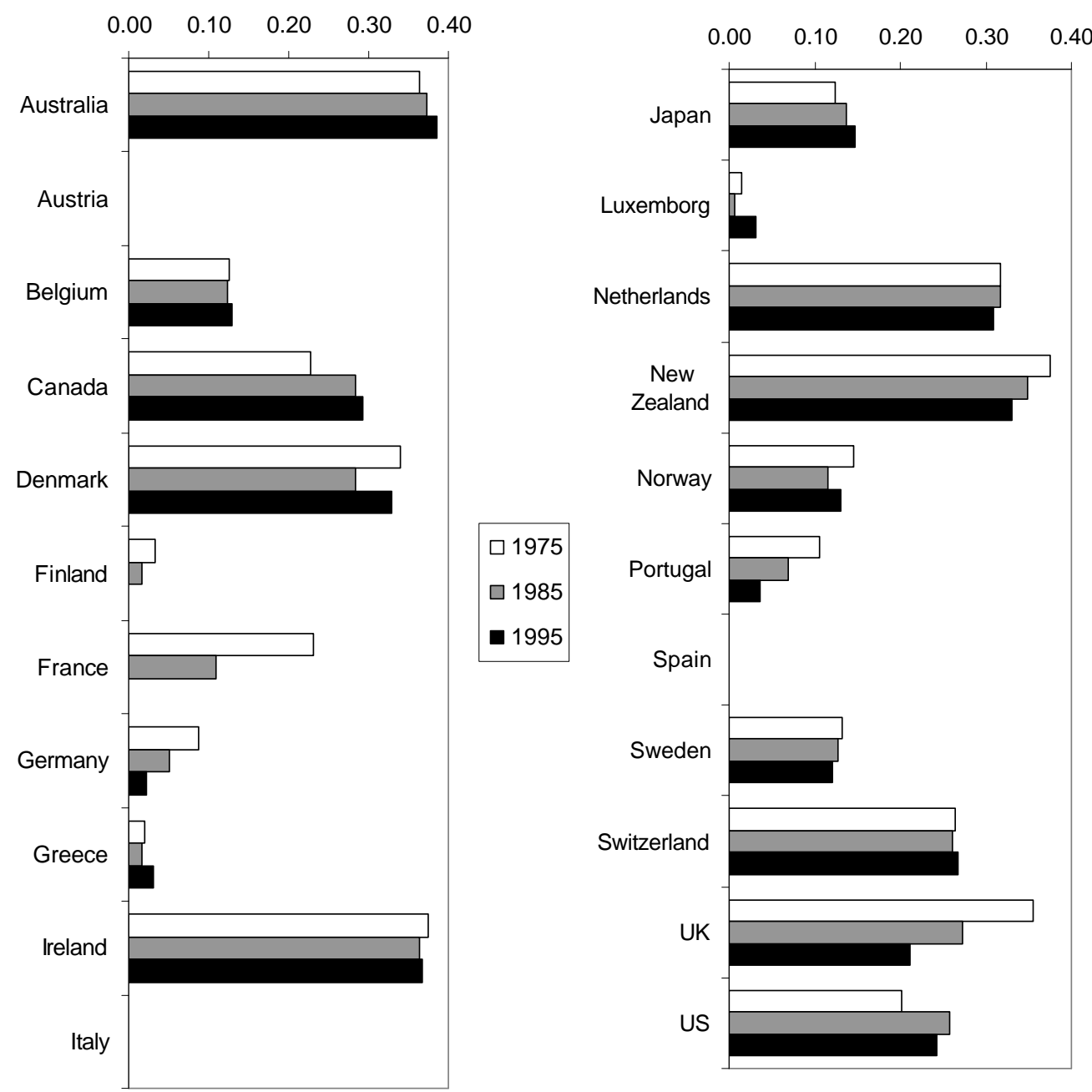

Source: Disney (2004), Figure 4. The dates refer to the date at which the generation member reaches age 55 . 